\title{
Antiemetic effects of dexamethasone and ondansetron combination during cesarean sections under spinal anaesthesia
}

\author{
*Demirhan A ${ }^{1}$, Tekelioglu YU ${ }^{1}$, Akkaya A ${ }^{1}$, Ozlu T², Yildiz I ${ }^{1}$, Bayir $\mathrm{H}^{1}$, Kocoglu $\mathrm{H}^{1}$, Duran $\mathrm{B}^{2}$
}

1. Department of Anesthesiology and Reanimation, Abant Izzet Baysal University Medical School, Bolu, Turkey

2. Department of Obstetrics and Gynecology, Abant Izzet Baysal University Medical School, Bolu, Turkey

\begin{abstract}
Background: Nausea and vomiting are frequently seen in patients undergoing cesarean section (CS) under regional anesthesia. We aimed to compare the antiemetic efficacy of ondansetron and dexamethasone combination with that of the use of each agent alone to decrease the incidence of post-delivery intraoperative nausea and vomiting (IONV) during CS under spinal anesthesia.

Objective: To compare the antiemetic efficacy of ondansetron and dexamethasone combination with that of the single use of each agent to decrease the incidence of postdelivery IONV during CS under spinal anesthesia.

Methods: A randomized, prospective, double blind study was performed on 90 patients undergoing planned CS under spinal anesthesia. Patients received $4 \mathrm{mg}$ ondansetron in Group O, $8 \mathrm{mg}$ dexamethasone in GroupD, 4mg ondansetron $+8 \mathrm{mg}$ dexamethasone in Group OD intravenously within 1-2 minutes after the umbilical cord was clamped. Frequency of postdelivery IONV episodes was recorded.

Results: A total of 86 eligible patients were included in the study. There were 29 patients in Group O, 29 patients in Group $\mathrm{D}$ and 28 patients in Group OD. There were no statistically significant difference between the groups in terms of baseline characteristics and intraoperative managements. Frequency of intraoperative nausea, retching and vomiting experiences were similar between the groups $(\mathrm{p}>0.05)$.

Conclusion: Single dose $4 \mathrm{mg}$ ondansetron, $8 \mathrm{mg}$ dexamethasone, or combined use of $8 \mathrm{mg}$ dexamethasone $+4 \mathrm{mg}$ ondansetron, given intravenously is all effective agents for the control of postdelivery IONV. Combined use of dexamethasone and ondansetron for the same indication does not seem to increase the antiemetic efficacy.

Keywords: Emesis, nausea and vomiting, intraoperative; ondansetron, 5-HT3 antagonists, dexamethasone African Health Sciences 2013; 13(2): 475 - 482 http://dx.doi.org/10.4314/ahs.v13i2.39
\end{abstract}

\section{Introduction}

Nausea and vomiting is seen in almost $80 \%$ of the patients undergoing cesarean section (CS) under regional anesthesia ${ }^{1-3}$. Many different factors like psychogenic factors, surgical procedure itself, traction of the visceral peritoneum, uncorrected hypotension, administration of opioid drugs and uterotonic agents can lead to nausea and vomiting ${ }^{4-6}$. Antiemetic drugs can be used in the management of intraoperative nausea and vomiting (IONV) and they are generally administered after the umbilical cord is clamped ${ }^{2,7-9}$. Ondansetron is a selective antagonist of the 5hydroxytryptamine $3\left(5-\mathrm{HT}_{3}\right)$ receptors and is a very effective agent in the prevention and treatment of nausea and vomiting. It is effective in the prevention

\section{*Corresponding author:}

Dr. Abdullah Demirhan

Department of Anesthesiology and Reanimation Abant Izzet Baysal University Medical School 14280 Golkoy, BOLU

Phone: +90 3742534656 / 3129

E mail: dr_demirhan1@hotmail.com and treatment of chemotherapy induced ${ }^{10}$, intraoperative ${ }^{7}$ and postoperative nausea and vomiting $^{11,12}$. It decreases the nausea and vomiting that occurs during CS but it cannot completely control the symptoms.

Dexamethasone is a corticosteroid with antiemetic and high anti-inflammatory effects. Use of dexamethasone in combination with the other drugs has been reported to increase the antiemetic or analgesic efficacy, and minimal side effects have been reported when it is used as a single agent ${ }^{13-16}$. The mechanism for the antiemetic effect of dexamethasone has been incompletely understood but it is thought to be caused by the inhibition of prostaglandin synthesis, by showing antiinflammatory efficacy and by causing a decrease in the release of endogenous opiates ${ }^{17,18}$. As an antiemetic agent, it has been used at a dose ranging between $2.5-10 \mathrm{mg} /$ day $^{19,20}$.

Since nausea and vomiting can occur by a variety of different mechanisms, combinations of different antiemetics are used to prevent or treat these 
symptoms ${ }^{6,21}$. By the help of these combinations, multiple routes that can lead to nausea and vomiting can be blocked ${ }^{22}$. Effect of addition of dexamethasone to ondansetron in the control of postoperative nausea and vomiting (PONV) has been studied before, but we could not find any study in the literature that investigated the efficacy of this combination for the control of postdelivery IONV. In this study, we aimed to compare the antiemetic efficacy of ondansetron and dexamethasone combination with that of the single use of each agent to decrease the incidence of postdelivery IONV during CS under spinal anesthesia.

\section{Methods}

Approval from the clinical research ethics committee of Abant Izzet Baysal University was obtained before the initiation of the study. All participants provided a written informed consent. This randomized, prospective, double blind, study was performed on 90 ASA physical status I-II female patients, between 20-40 years of age undergoing a planned CS under spinal anesthesia. Patients with a gastrointestinal disease, drug allergies, infection, diabetes, glaucoma, preeclampsia, eclampsia, a psychiatric disorder and those patients who took an antiemetic agent in the last 24 hours were excluded from the study.

Antiemetic drugs were prepared as a $5 \mathrm{~mL}$ solution diluted with normal saline in similar syringes, by a second anesthetist at the initiation of surgery at a separate room and there were also syringes which included only $5 \mathrm{~mL}$ of normal saline. Two syringes were given by the second anesthetist to the anesthetist who was unaware of the content of the syringe and would administer it in a double-blind fashion. A total of 30 patients were randomly allocated to each of the 3 groups. The randomization was performed by the use of sequentially numbered, opaque, sealed envelopes. Patients received either $4 \mathrm{mg}$ ondansetron (Zofer $2 \mathrm{ml} / 4 \mathrm{mg}$, Adeka) diluted to $5 \mathrm{~mL}$ by normal saline $+5 \mathrm{~mL}$ normal saline (Group O), $8 \mathrm{mg}$ dexamethasone (Deksamet 2ml/8mg, Osel) diluted to $5 \mathrm{~mL}$ by normal saline $+5 \mathrm{~mL}$ normal saline (group D) or $4 \mathrm{mg}$ ondansetron diluted to $5 \mathrm{~mL}$ by normal saline $+8 \mathrm{mg}$ dexamethasone diluted to $5 \mathrm{~mL}$ by normal saline (Group OD) intravenously, within 1-2 minutes after the umbilical cord was clamped.

At the operating room, initially, standard monitorization that included electrocardiogram, noninvasive arterial blood pressure measurement and pulse oximetry was applied to all patients. All patients received $15-20 \mathrm{~mL} / \mathrm{kg}$ (1500 $\mathrm{ml}$ maximum) normal saline before the intervention. Spinal anesthesia was performed using a 25-gauge spinal needle (Braun Melsungen, Germany), while the patient is in the sitting position, through the L3-4 interspace (or alternatively through the L2-3 or L4-5 interspaces). $2.4-2.8 \mathrm{~mL}$ (depending on patients height) of $0.5 \%$ heavy marcaine (Marcaine Spinal Heavy Ampul \%0.5, Astrazenaca) was administered to the subarachnoid space. Patients were than moved to supine position, and to prevent spinal anesthesia induced hypotension, patients were infused normal saline at a rate of 125 $\mathrm{ml} / \mathrm{hr}$, operation table was given a 15-20 degrees left lateral tilt to decrease the aortocaval compression caused by the uterus. Oxygen was delivered to all patients at a rate of 2-3 L/ min via a face mask. Before the surgical incision, the level of sensorial blockage was evaluated by pinprick test, and the highest level of blockade was determined. Patients in whom the level of analgesia was insufficient were excluded from the study, and were given general anesthesia. Non-invasive blood pressure measurements were obtained from each patient at 1-3 min intervals, and in case of hypotension blood pressure measurement intervals were shortened to $1 \mathrm{~min}$. We have assumed that systolic blood pressure $<100 \mathrm{mmHg}$ or $>20 \%$ decrease in systolic blood pressure as hypotension. We treated hypotension with increasing the infusion rate of normal saline, and administering 5-10 $\mathrm{mg}$ of intravenous ephedrine (Efedrin Ampul $1 \mathrm{ml} / 50 \mathrm{mg}$, Osel) in necessary cases was planned. After delivery of the fetus, 10 units of oxytocin $/ 500 \mathrm{~mL} 0.9 \%$ normal saline administered at a rate of $125 \mathrm{~mL} /$ hour to increase the uterine contractility.

During the intraoperative post-delivery period, nausea, retching and vomiting episodes were recorded by an anesthetist who was blinded to the drug administered to the patient. Besides questioning the patient in every 3 minutes about these emetic symptoms, the patient was also requested to report the symptoms that occur at the intervals. Drug related complications were recorded during the study period. A standardized surgical technique was used in all cesarean section's except for the tubal ligation procedure performed in some but not all of the cases.

For the statistical analysis, SPSS software for Windows version 15.0 (SPSS Inc., Chicago, IL, USA) was used. All sample sizes and power calculations were 2-tailed with an á level of .05. The original sample size of 75 individuals permitted $91 \%$ and $89 \%$ power for detecting effect sizes of 0.2 and 0.3 , respectively. The target sample size of 90 individuals 
included an anticipated 10\% dropout in the best medical therapy group. Continuous data are presented as mean \pm standard deviation. One-way ANOVA test and test were used for parametric data analysis, and Kruskal-Wallis test, Mann Whitney $\mathrm{U}$ test, Chi-square and Fisher's exact tests were used to analyze non-parametric data. $\mathrm{P}<0.05$ was considered statistically significant.

\section{Results}

A total of 90 patients were initially included in the study. Two patients were excluded from the study because of a low level of sensorial blockade as detected by the pinprick test. In spite of a sufficient level of sensorial blockade, two patients were also excluded from the study since they required sedation with propofol. The remaining 86 eligible patients, 29 were in Group O, 29 were in Group D and 28 were in Group OD (figure 1).

Levels of the sensorial blockade of the 86 patients were sufficient for the surgical procedure and were between $\mathrm{T} 2$ and $\mathrm{T} 6$ with no significant difference between the groups ( $p>0.05)$ (table 2). All patients included in the study had an uncomplicated CS. There were no significant differences between the groups in terms of baseline patient characteristics $(\mathrm{p}>0.05)$ (table 1$)$, and intraoperative managements $(\mathrm{p}>0.05)$ (table 2$)$.

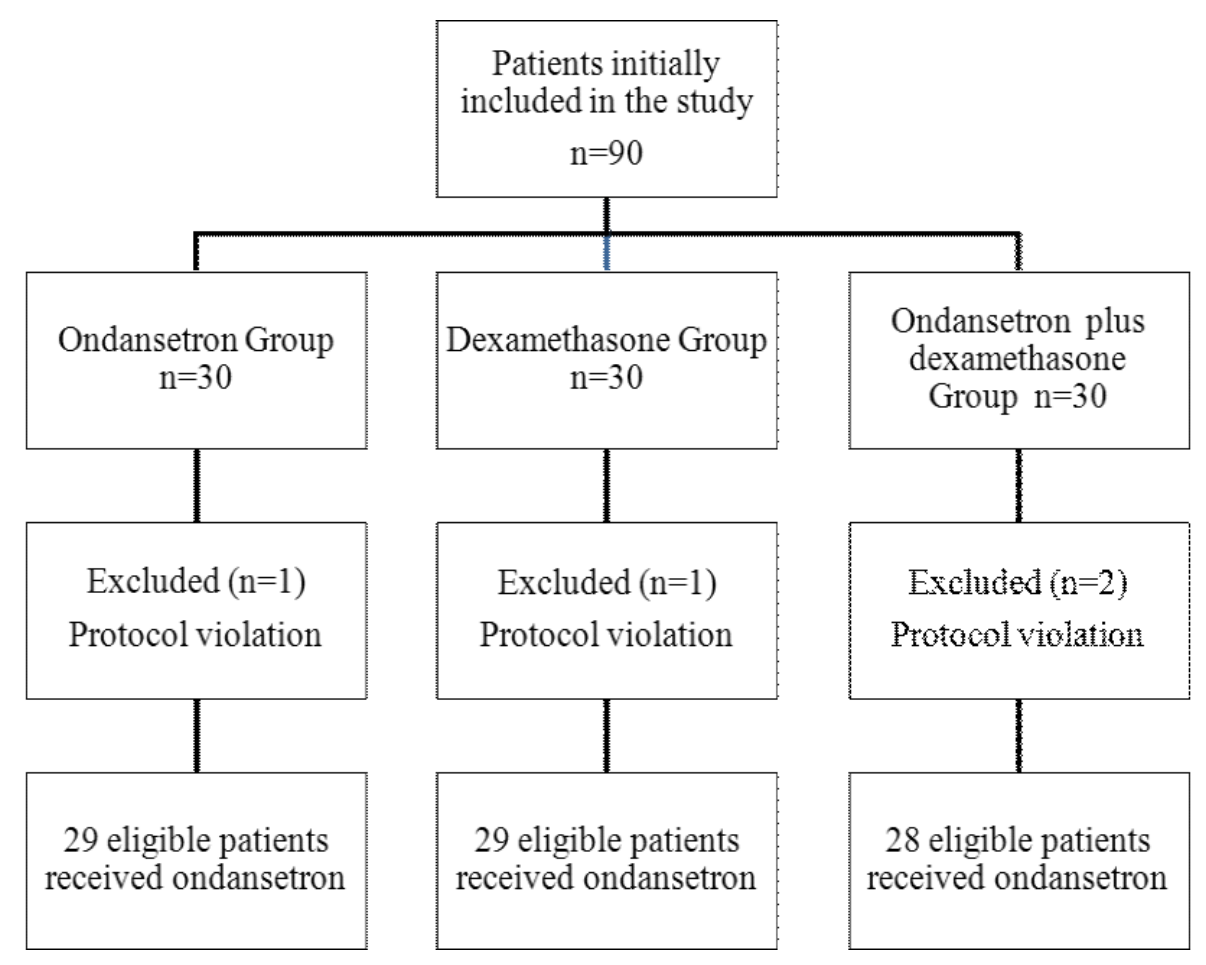

Figure 1: Study profile

Table 1: Baseline patient characteristics

\begin{tabular}{lcll}
\hline & $\begin{array}{l}\text { Ondansetron } \\
\text { Group (n=29) }\end{array}$ & $\begin{array}{l}\text { Dexamethason } \\
\text { e Group (n=29) }\end{array}$ & $\begin{array}{l}\text { Ondansetron plus } \\
\text { Dexamethasone Group } \\
(\mathbf{n = 2 8})\end{array}$ \\
\hline Age, years & $30 \pm 6$ & $29 \pm 4$ & $29 \pm 4$ \\
Weight, kg & $74 \pm 12$ & $73 \pm 11$ & $79 \pm 14$ \\
Height, cm & $161 \pm 4$ & $162 \pm 6$ & $162 \pm 5$ \\
Gestational age (weeks) & $37 \pm 1$ & $37 \pm 1$ & $37 \pm 1$ \\
Multiparous (\%) & $17(58)$ & $22(75)$ & $18(64)$ \\
Smoking (\%) & $3(10)$ & $3(10)$ & $4(14)$ \\
History of motion sickness (\%) & $3(10)$ & $9(31)$ & $7(25)$ \\
History of previous postoperative & $5(17)$ & $2(7)$ & $3(11)$ \\
emesis (\%) & & $118 \pm 15$ & $120 \pm 13$ \\
Baseline blood pressure (mm Hg) & $121 \pm 13$ & & \\
\hline
\end{tabular}

Values are expressed as means $\pm \mathrm{SD}$, numbers or numbers (\%) of patients. 
Table 2: Information about the intraoperative managements, ephedrine needs for the correction of hypotension and sensorial blockade levels of patients in the groups

\begin{tabular}{lccc}
\hline & $\begin{array}{c}\text { Ondansetron } \\
\text { group } \\
(\mathbf{n}=29)\end{array}$ & $\begin{array}{c}\text { Dexamethasone } \\
\text { group } \\
(\mathbf{n}=29)\end{array}$ & $\begin{array}{c}\text { Ondansetron plus } \\
\text { Dexamethasone group } \\
(\mathbf{n}=28)\end{array}$ \\
\hline Uterus exteriorization, $\mathbf{n}$ & 29 & 29 & 28 \\
Operation time (min) & $35 \pm 10$ & $35 \pm 12$ & $41 \pm 14$ \\
Uterus exteriorization time (min) & $3.6 \pm 1.6$ & $4.1 \pm 2.2$ & $3.9 \pm 1.6$ \\
I-D Interval (min) & $2.5 \pm 1.5$ & $3 \pm 1.9$ & $2.9 \pm 1.6$ \\
U-D Time (sec) & $49 \pm 37$ & $44 \pm 34$ & $51 \pm 38$ \\
Tubal ligation during cesarean section & $7(24.1)$ & $1(3.4)$ & $5(17.9)$ \\
(\%) & $4(14)$ & $2(7)$ & $7(25)$ \\
Number of patients that had & & & $11(39.3)$ \\
hypotension who required ephedrine, & $13(44.8)$ & $19(65.5)$ & \\
Sensory block & & & \\
T4 (\%) & &
\end{tabular}

Values are expressed as means $\pm \mathrm{SD}$, numbers or numbers (\%) of patients.

I-D interval: interval from skin incision to delivery of fetus, U-D interval: interval from uterine incision to delivery of fetus

Of the 86 patients, tubal ligation was performed in 13 of the cases. The operation duration of patients that had undergone tubal ligation was significantly longer than those who had not undergone this procedure $(\mathrm{p}=0.01)$ (table 4$)$. But, there was no significant difference between the incidence of emetic symptoms of the patients that had or had not undergone tubal ligation in spite of different durations of surgery ( $p>0.05)$ (table 4). Four (14\%) patients in Group O, $2(7 \%)$ patients in Group D and 7 (25\%) patients in Group OD had hypotension all of which occurred after the delivery period. There was no difference between the incidence of intraoperative emetic symptoms of the patients between the groups ( $\mathrm{p}>0.05$ ) (table 3$) .86 .2 \%$ of patients in Group O, $72.4 \%$ of patients in Group D and $64.3 \%$ of patients in Group OD were free of these symptoms. One patient from Group D exhibited vomiting and none from the other groups. Extrapyramidal side effects or cardiac arrhythmias occurred in none of the patients. Transient headache lasting less than 10 minutes was the most common side effect and was observed in 2 patients from group $\mathrm{O}$ and 3 patients from Group OD.

Table 3: Comparison of the duration of surgery and the frequency of emetic symptoms between patients that had or had not undergone tubal ligation

\begin{tabular}{llll}
\hline & $\begin{array}{l}\text { With tubal } \\
\text { ligation }(\mathbf{n}=\mathbf{1 3})\end{array}$ & $\begin{array}{l}\text { Without tubal } \\
\text { ligation } \\
(\mathbf{n = 7 3 )}\end{array}$ & p value \\
\hline Operation time (min) & $36 \pm 12.5$ & $44 \pm 11$ & 0.01 \\
Incidence of nausea & $3(23)$ & $19(26)$ & 0.563 \\
Incidence of retching & $2(15.3)$ & $5(6.8)$ & 0.285 \\
Incidence of vomiting & $\mathrm{O}(0)$ & $1(1)$ & 0.849 \\
\hline
\end{tabular}

Values are expressed as means \pm SD or numbers (\%) of patients. 
Table 4: Comparison of the emetic symptoms that occurred during intraoperative period

\begin{tabular}{lllll}
\hline & $\begin{array}{l}\text { Ondansetron } \\
\text { group }\end{array}$ & $\begin{array}{l}\text { Dexamethasone } \\
\text { group }\end{array}$ & $\begin{array}{l}\text { Ondansetron }+ \\
\text { Dexamethasone } \\
\text { group }\end{array}$ & $\begin{array}{l}\text { p } \\
\text { value }\end{array}$ \\
\hline $\begin{array}{l}\text { Number of patients } \\
\begin{array}{l}\text { No symptoms (no nausea, } \\
\text { retching, or vomiting) }\end{array}\end{array}$ & 29 & 29 & 28 & 0.158 \\
$\begin{array}{l}\text { Incidence of Nausea } \\
\text { Incidence of Retching }\end{array}$ & $4(86.2)$ & $21(72.4)$ & $18(64.3)$ & \\
Incidence of Vomiting & $3(10.3)$ & $8(27.6)$ & $10(35.7)$ & 0.694 \\
\hline
\end{tabular}

Values are expressed as numbers or numbers (\%) of patients.

\section{Discussion}

This randomized, prospective, double blind study demonstrated that CSs performed under spinal anesthesia using $8 \mathrm{mg}$ intravenous dexamethasone as a single agent for the control of postdelivery IONV is as effective as $4 \mathrm{mg}$ ondansetron with no increase in the side effect profile. Combined use of these agents for the same indication does not seem to increase the efficacy when compared with the ondansetron or dexamethasone alone.

The precise etiology of IONV remains unknown and various factors have been implicated ${ }^{4-}$ ${ }^{6}$. Hypotension is probably the most important cause of IONV that occurs during CS under spinal anesthesia. Hypotension can induce the emetic symptoms by leading to cerebral hypoperfusion ${ }^{6}$. Prevention of hypotension is therefore important for the prevention of IONV. We tried to take the necessary measures to prevent hypotension in all of our patients. Although recent studies favor the use of phenylephrine over ephedrine for the control of intraoperative hypotension ${ }^{23}$, we could not use this drug since it is not commercially found in our country. In our study we especially evaluated the incidence of post delivery IONV. Because the nausea and vomiting before the delivery period is especially related with spinal anesthesia induced hypotension which can be prevented by performing the necessary preventive measures. Besides, in our cases, in contrast to those reported in the previous studies ${ }^{7,9}$ interval from skin incision to delivery of fetus and the interval from uterine incision to delivery of fetus in all groups were very short. So the predelivery period was very short in the present study. Depending on our previous observations, we thought that it would be better to investigate the nausea and vomiting in the postdelivery period which is more difficult to control.
Although majority of hypotension during spinal anesthesia for CS occur before the delivery period, none of our patients experienced hypotension during this period as a result of adequate preventive measures. All of the hypotension cases in our study occurred after the delivery period. All patients developing hypotension also showed emetic symptoms sequentially, which resolved simultaneously within a short time with the correction of hypotension.

The baseline characteristics and intraoperative managements of all participants in the groups were similar in our study. The surgical procedure was standard in all of the cases except performance of tubal ligation in some of the cases, and this caused a prolongation in the duration of surgery. But, we found that this prolongation had no effect in the incidence of post delivery IONV. Ondansetron is a potent antiemetic agent which has been effectively used for the control of IONV and PONV. In clinical practice, it is commonly used at a dose of $4 \mathrm{mg}$ intravenously ${ }^{9,24-28}$. Dershwitz et al. studied 6 different doses of ondansetron for the prevention of PONV and they recommended the $4 \mathrm{mg}$ dose as a result of their study ${ }^{26}$. Abouleish et al. found that use of $4 \mathrm{mg}$ ondansetron during CS decreased the occurrence of the emetic symptoms significantly when compared with the placebo $(\% 36$ vs. $\% 58)^{24}$. In our study we also used ondansetron at a dose of $4 \mathrm{mg}$ and the emetic symptoms observed in Group $\mathrm{O}$ was similar to the previous studies. Combined use of antiemetics can act from several different ways in controlling nausea and vomiting symptoms, and therefore can be more effective than using single agents ${ }^{22}$. Some studies in the literature 
compared the antiemetic efficacy of dexamethasone for the prevention of PONV with other agents, or investigated the efficacy of combining dexamethasone with other antiemetic agents for the same purpose. D'Souza et al. compared dexamethasone with ondansetron for the prevention of PONV after laparoscopic gynecologic surgery and found that dexamethasone decreased the incidence of PONV and use of single dose of dexamethasone was safe, had a lesser cost and could be alternative to single dose ondansetron in this patient population ${ }^{19}$. Bhattarai et al. compared use of ondansetron alone with combined use of $4 \mathrm{mg}$ ondansetron plus $8 \mathrm{mg}$ dexamethasone in the control of PONV in patients undergoing laparoscopic surgery and found that the combined use of two agents was more effective ${ }^{25}$. The combination was also safe and well tolerated by the patients. Several other studies in the literature also demonstrated that combined use of dexamethasone with other antiemetics decreases the incidence of PONV ${ }^{14,15,29,30}$. In our study we investigated the efficacy of $8 \mathrm{mg}$ dexamethasone alone or in combination with $4 \mathrm{mg}$ ondansetron for the control of IONV. Since these 2 agents act by different antiemetic mechanisms, we did not decrease the dosage of each agent during combined therapy. As emetic symptoms are frequently observed in patients undergoing CS under spinal anesthesia, we thought it would not be ethical to form a placebo group for our study. Absence of significant difference in the incidence of emetic symptoms of patients in Group D from the other groups shows, as in the previous studies ${ }^{19}$, that dexamethasone is an effective antiemetic agent. Incidence of emetic symptoms in Group OD was slightly higher from the other groups although this difference was not statistically significant. We thought that this difference was due to a greater rate of hypotension observed in this group which is demonstrated in Table 2 by a higher need for ephedrine use. Occurrence of transient headache in 2 patients from Group $\mathrm{O}$ and in 3 patients from Group OD while it did not occur in any of the patients in group $\mathrm{D}$ was an indicator that single dose use of dexamethasone did not cause an increase in the side effect profile and was well tolerated by the patients.

The main limitation of the present study is that we administered dexamethasone within 1-2 minutes after the umbilical cord was clamped. Wang et $\mathrm{al}^{31}$ have shown that dexamethasone took long to achieve its antiemetic effects. This may explain why there was lack of effect in the dexamethasone and ondansetron combined arm in our study.

\section{Conclusion}

Single dose $8 \mathrm{mg}$ dexamethasone or $4 \mathrm{mg}$ ondansetron given intravenously are both effective agents for the control of postdelivery IONV. However, combined use of these agents does not seem to increase the efficacy over that achieved by the single use of each agent. Further randomized, controlled trials with a larger sample size are needed to clarify the efficacy of these agents in the control of postdelivery IONV.

\section{References}

1. Lussos SA, Bader AM, Thornhill ML, Datta S. The antiemetic efficacy and safety of prophylactic metoclopramide for elective cesarean delivery during spinal anesthesia. Regional anesthesia 1992;17:126-30.

2. Santos A, Datta S. Prophylactic use of droperidol for control of nausea and vomiting during spinal anesthesia for cesarean section. Anesthesia and analgesia 1984;63:85-7.

3. Harmon D, Ryan M, Kelly A, Bowen M. Acupressure and prevention of nausea and vomiting during and after spinal anaesthesia for caesarean section. British journal of anaesthesia 2000;84:463-7.

4. Crocker JS, Vandam LD. Concerning nausea and vomiting during spinal anesthesia. Anesthesiology 1959;20:587-92.

5. Ratra CK, Badola RP, Bhargava KP. A study of factors concerned in emesis during spinal anaesthesia. British journal of anaesthesia 1972;44:1208-11.

6. Balki M, Carvalho JC. Intraoperative nausea and vomiting during cesarean section under regional anesthesia. International journal of obstetric anesthesia 2005;14:230-41.

7. Pan $\mathrm{PH}$, Moore $\mathrm{CH}$. Intraoperative antiemetic efficacy of prophylactic ondansetron versus droperidol for cesarean section patients under epidural anesthesia. Anesthesia and analgesia 1996;83:982-6.

8. Balki M, Kasodekar S, Dhumne S, Carvalho JC. Prophylactic [corrected] granisetron does not prevent postdelivery nausea and vomiting during elective cesarean delivery under spinal anesthesia. Anesthesia and analgesia 2007;104:679-683.

9. Pan PH, Moore CH. Comparing the efficacy of prophylactic metoclopramide, ondansetron, and placebo in cesarean section patients given epidural 
anesthesia. Journal of clinical anesthesia 2001;13:4305.

10. .Hesketh PJ. Comparative review of 5-HT3 receptor antagonists in the treatment of acute chemotherapy-induced nausea and vomiting. Cancer investigation 2000;18:163-73.

11. .Leeser J, Lip H. Prevention of postoperative nausea and vomiting using ondansetron, a new, selective, 5-HT3 receptor antagonist. Anesthesia and analgesia 1991;72:751-55.

12. Scuderi P, Wetchler B, Sung YF, Mingus M, DuPen S, Claybon L, Leslie J, Talke P, Apfelbaum J, Sharifi-Azad S, et al. Treatment of postoperative nausea and vomiting after outpatient surgery with the 5-HT3 antagonist ondansetron. Anesthesiology 1993;78:15-20.

13. Wang JJ, Ho ST, Lee SC, Liu YC, Liu YH, Liao YC. The prophylactic effect of dexamethasone on postoperative nausea and vomiting in women undergoing thyroidectomy: a comparison of droperidol with saline. Anesthesia and analgesia 1999;89:200-03.

14. Tzeng JI, Wang JJ, Ho ST, Tang CS, Liu YC, Lee SC. Dexamethasone for prophylaxis of nausea and vomiting after epidural morphine for post-Caesarean section analgesia: comparison of droperidol and saline. British journal of anaesthesia 2000;85:865-8.

15. De Oliveira GS, Jr., Castro-Alves LJ, Ahmad S, Kendall MC, McCarthy RJ. Dexamethasone to prevent postoperative nausea and vomiting: an updated meta-analysis of randomized controlled trials. Anesthesia and analgesia 2013;116:58-74.

16. Parrington SJ, O'Donnell D, Chan VW, BrownShreves D, Subramanyam R, Qu M, Brull R. Dexamethasone added to mepivacaine prolongs the duration of analgesia after supraclavicular brachial plexus blockade. Regional anesthesia and pain medicine 2010;35:422-6

17. Wattwil M, Thorn SE, Lovqvist A, Wattwil L, Gupta A, Liljegren G. Dexamethasone is as effective as ondansetron for the prevention of postoperative nausea and vomiting following breast surgery. Acta anaesthesiologica Scandinavica 2003;47:823-7.

18. Holte K, Kehlet H. Perioperative single-dose glucocorticoid administration: pathophysiologic effects and clinical implications. Journal of the American College of Surgeons 2002;195:694-712.

19. D'Souza N, Swami M, Bhagwat S. Comparative study of dexamethasone and ondansetron for prophylaxis of postoperative nausea and vomiting in laparoscopic gynecologic surgery. International journal of gynaecology and obstetrics 2011;113:124-7.

20. De Oliveira GS Jr, Castro-Alves LJ, Ahmad S, Kendall MC, McCarthy RJ. Dexamethasone to prevent postoperative nausea and vomiting: an updated meta-analysis of randomized controlled trials. Anesthesia and analgesia 2013;116:58

21. Song JW, Park EY, Lee JG, Park YS, Kang BC, Shim YH. The effect of combining dexamethasone with ondansetron for nausea and vomiting associated with fentanyl-based intravenous patient-controlled analgesia. Anaesthesia 2011;66:263-7.

22. Wu JI, Lo Y, Chia YY, Liu K, Fong WP, Yang LC, Tan PH. Prevention of postoperative nausea and vomiting after intrathecal morphine for Cesarean section: a randomized comparison of dexamethasone, droperidol, and a combination. International Journal of Obstetric Anesthesia 2007;16:122-7.

23. Lin FQ, Qiu MT, Ding XX, Fu SK, Li Q. Ephedrine versus phenylephrine for the management of hypotension during spinal anesthesia for cesarean section: an updated metaanalysis. CNS neuroscience \&o therapeutics 2012;18:591-7.

24. Abouleish EI, Rashid S, Haque S, Giezentanner A, Joynton P, Chuang AZ. Ondansetron versus placebo for the control of nausea and vomiting during Caesarean section under spinal anaesthesia. Anaesthesia 1999;54:479-82.

25. Bhattarai B, Shrestha S, Singh J. Comparison of ondansetron and combination of ondansetron and dexamethasone as a prophylaxis for postoperative nausea and vomiting in adults undergoing elective laparoscopic surgery. Journal of emergencies, trauma, and shock 2011;4:168-72.

26. Dershwitz M, Conant JA, Chang Y, Rosow CE, Connors PM. A randomized, double-blind, dose-response study of ondansetron in the prevention of postoperative nausea and vomiting. Journal of clinical anesthesia 1998;10:31420.

27. Manullang TR, Viscomi CM, Pace NL. Intrathecal fentanyl is superior to intravenous ondansetron for the prevention of perioperative nausea during cesarean delivery with spinal anesthesia. Anesthesia and analgesia 2000;90:11626. 
28. Griffiths JD, Gyte GM, Paranjothy S, Brown HC, Broughton HK, Thomas J. Interventions for preventing nausea and vomiting in women undergoing regional anaesthesia for caesarean section. Cochrane Database Syst Rev. 2012;12;9:CD007579.

29. Thangaswamy CR, Rewari V, Trikha A, Dehran M, Chandralekha. Dexamethasone before total laparoscopic hysterectomy: a randomized controlled dose-response study. Journal of anesthesia 2010;24:24-30.
30. Wang JJ, Ho ST, Wong CS, Tzeng JI, Liu HS, Ger LP. Dexamethasone prophylaxis of nausea and vomiting after epidural morphine for postCesarean analgesia. Canadian journal of anaesthesia 2001;48:185-90.

31. Wang JJ, Ho ST, Tzeng JI, Tang CS. The effect of timing of dexamethasone administration on its efficacy as a prophylactic antiemetic for postoperative nausea and vomiting. Anesth Analg. 2000;91:136-9. 